Published as: Liu, X., Derudder, B. \& Liu, Y. (2011), Featured graphic: GDP, livability, population, and income inequality of world cities . Environment and Planning A, vol. 43 (10), pp. $2255-2256$.

\title{
GDP, livability, population, and income inequality of world cities
}

Xingjian Liu ${ }^{1}$ (xl306@cam.ac.uk), Ben Derudder ${ }^{2}$ (ben.derudder@ugent.be), and Yaolin Liu ${ }^{3}$ (yaolin610@163.com)

1. Department of Geography, University of Cambridge, UK

2. Department of Geography, Ghent University, Belgium

3. School of Resource and Environmental Science, Wuhan University, China

In this graphic, we combine information on four different indicators to assess cities' social, economic, and environmental characteristics in a global context: 1) Gross Domestic Product (GDP) per capita which reflects cities' economic competitiveness; 2) livability measures focusing on cities' social issues such as safety, education and health; 3 ) income inequality of the country that individual cities locate; and 4) urban populations. Based on the data availability in these four datasets, a total of 98 cities across the world are presented in this graphic. Cities' standardized, logged GDP per capita values are plotted on the X-axis, against their standardized livability measurements on the $Y$-axis. Data points represent individual cities and their sizes are proportional to cities' populations. Darker colour of data points represent greater income inequality, and vice versa. Centering at the coordinate origin, the plot is divided into four quadrants. Upper right quadrant: Cities with above-average values in dimensions are on the top of the global urban hierarchy, with relatively large populations, high-level livability, and well economic performance. Lower right quadrant: In this quadrant lie leading cities from the erstwhile 'Third World', which represent greater national income inequality, host large populations, and have comparatively low quality of living. Upper left quadrant: Cities in this category are primarily located in welfare states where income inequalities are lowest. Lower left quadrant: African cities dominant in this category, and are usually deemed as backwaters in the otherwise increasing integrated world economy, but by the inequality within their countries they vary greatly.

Source of data: Mercer's Quality of Living Survey 2007, Pricewaterhouse Coopers Global city GDP rankings 2008-2025, CityPopulation website 2010, United Nations Human Development Index 2010, all accessed online, March 2010.

Software: Matlab R2009a 


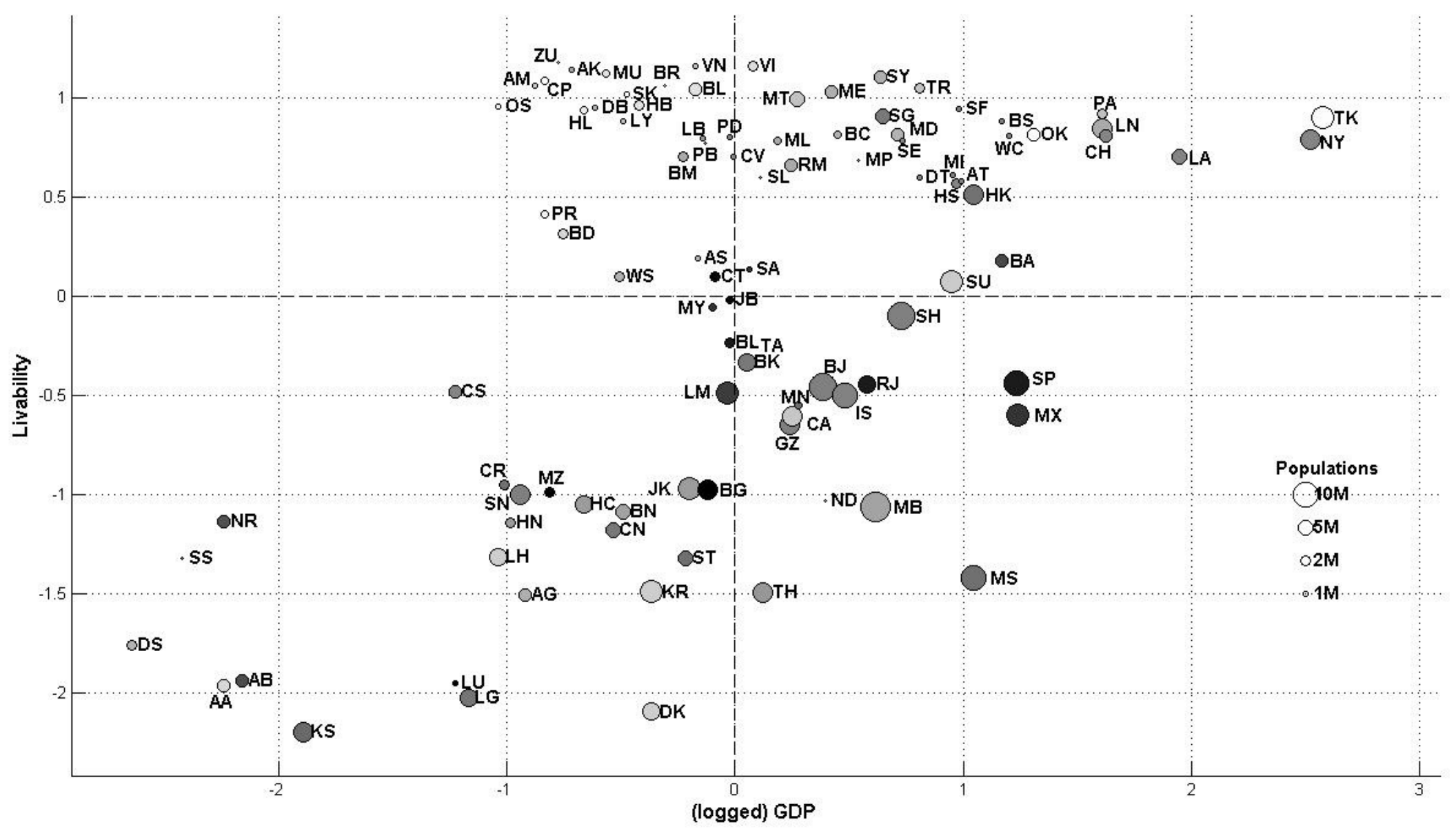

City codes: AA Addis Ababa; AB Abidjan; AG Algiers; AK Auckland; AM Amsterdam; AS Athens; AT Atlanta; BA Buenos Aires; BC Barcelona; BD Budapest; BG Bogota; BJ Beijing; BK Bangkok; BL Brasilia; BL Berlin; BM Birmingham; BN Bangalore; BR Brussels; BS Boston; CA Cairo; CH Chicago; CN Chennai; CP Copenhagen; CR Caracas; CS Casablanca; CT Cape Town; CV Cleveland; DB Dublin; DK Dhaka; DS Dares Salaam; DT Detroit; GZ Guangzhou; HB Hamburg; HC Ho Chi Minh City; HK Hong Kong; HL Helsinki; HN Hanoi; HS Houston; IS Istanbul; JB Johannesburg; JK Jakarta; KR Karachi; KS Kinshasa; LA Los Angeles; LB Lisbon; LG Lagos; LH Lahore; LM Lima; LN London; LU Luanda; LY Lyon; MB Mumbai; MD Madrid; ME Melbourne; MI Miami; ML Milan; MN Manila; MP Minneapolis; MS Moscow; MT Montreal; MU Munich; MX Mexico City; MY Monterrey; MZ Medellin; ND New Delhi; NR Nairobi; NY New York; OK Osaka; OS 


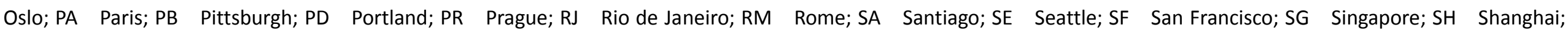

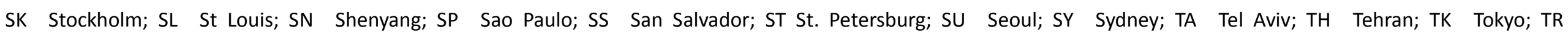
Toronto; VI Vienna; VN Vancouver; WC Washington; WS Warsaw; ZU Zurich.

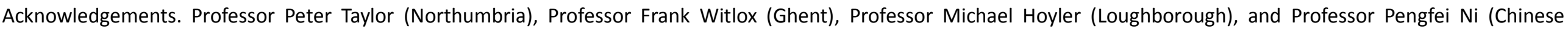
Academy of Social Sciences) 